\title{
Standard dermoscopy and videodermoscopy as tools for medical student dermatologic education
}

\author{
Hyunje G. Cho ${ }^{1}$, Sarah L. Sheu ${ }^{1}$, Audris Chiang ${ }^{1,2}$, Kristin M. Nord ${ }^{3}$
}

\begin{abstract}
1 Department of Dermatology, Stanford University School of Medicine, Stanford, CA, USA
2 University of California, Irvine School of Medicine, Irvine, CA, USA

3 Dermatology Service, VA Palo Alto Health Care System, Palo Alto, CA, USA
\end{abstract}

Key words: dermoscopy, videodermoscopy, education

Citation: Cho HG, Sheu SL, Chiang A, Nord KM. Standard dermoscopy and videodermoscopy as tools for medical student dermatologic education. Dermatol Pract Concept. 2018;8(1):39-42. DOI: https://doi.org/10.5826/dpc.0801a08

Received: August 20, 2017; Accepted: December 6, 2017; Published: January 31, 2018

Copyright: $@ 2018$ Cho et al. This is an open-access article distributed under the terms of the Creative Commons Attribution License, which permits unrestricted use, distribution, and reproduction in any medium, provided the original author and source are credited.

Funding: Stanford Medicine Teaching and Mentoring Academy Innovation Grant.

Competing interests: The authors have no conflicts of interest to disclose.

All authors have contributed significantly to this publication.

Corresponding author: Kristin M. Nord, MD, Department of Dermatology, Stanford University School of Medicine, 450 Broadway, Pavilion C-233, MC 5334, Redwood City, CA 94063, USA. Tel.650.721.7193. Email: knord@stanford.edu

\section{Introduction}

The ability to identify common benign and malignant skin lesions is augmented by the use of dermoscopy and is relevant to medical students pursuing careers in medicine, surgery, and subspecialties [1]. Medical students who received dermoscopy instruction as an adjunct to their skin examination education were more likely to examine a patient's skin during physical examination when evaluated one year after skin examination education [2]. Standard dermatoscopes, utilized in the aforementioned studies, permit a single user to view skin lesions in greater detail by incorporating 10-fold magnification. As with standard dermoscopy, videodermoscopy allows examination of microstructures within the epidermis and dermis. Videodermoscopy further enhances viewing by increasing the magnification potential to 50 -fold or greater and by enabling multiple users to visualize skin lesions concurrently (Figure 1). In this study, we aim to assess whether the use of videodermoscopy improves the ability of medical students to identify benign and malignant skin lesions.

\section{Methods}

Ninety second-year medical students were invited to participate in this study during a dermatologic education session. All students received a 45 -minute lecture on general dermatologic topics. The study consisted of a pre-test with 6 demographic questions and 13 knowledge-based analytic and image identification questions, followed by a 7-minute training session with a live patient where the dermatology resident used either a standard dermatoscope (DermLite DL3; 3Gen, San Juan Capistrano, CA, USA) or a videodermatoscope (Dino-Lite AM4115ZT; Dunwell Tech, Inc, Torrance, CA). Participants subsequently completed a post-test including the same 13 knowledge-based questions. In total, 54 students completed the study: 24 and 30 students received instruction using standard dermoscopy and videodermoscopy, respectively. Dermoscopic features of seborrheic keratoses, melanocytic nevi, and angiomata were demonstrated, and those of melanoma and blue nevi were discussed during training. Final analysis omitted 4 knowledge-based questions on lesions not 

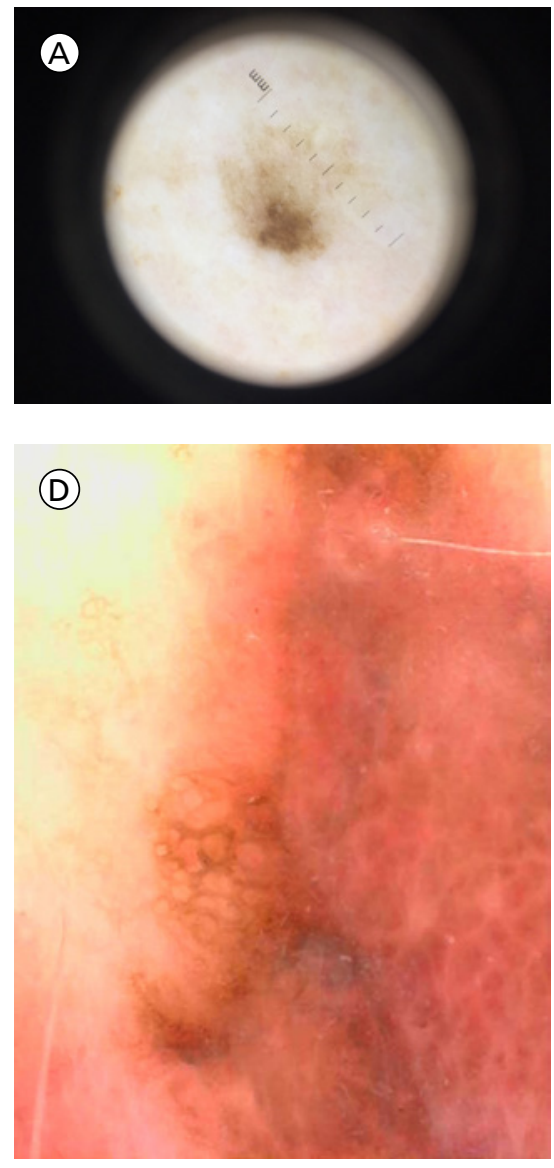
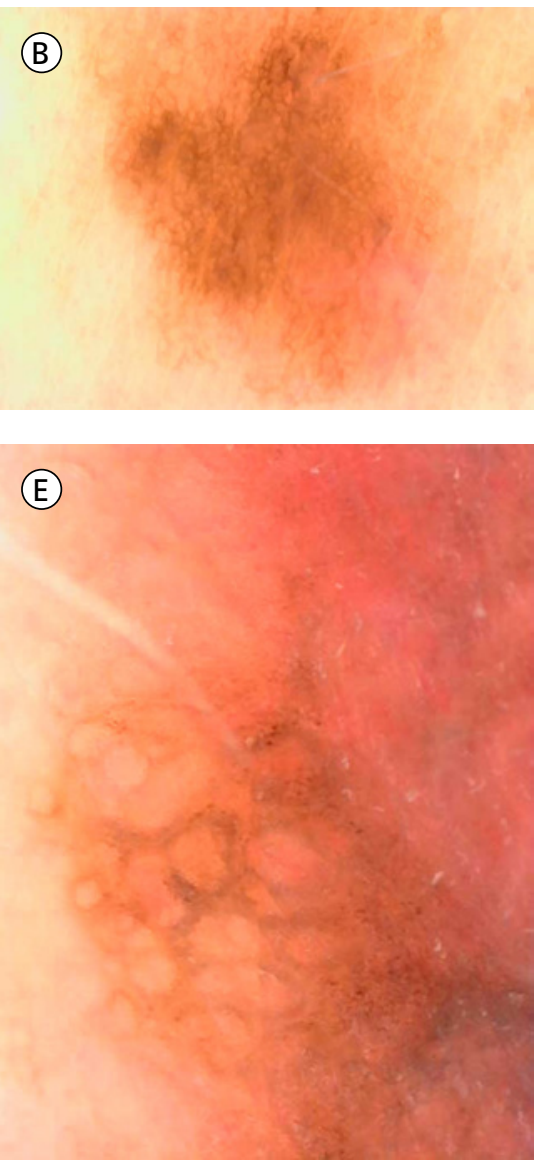

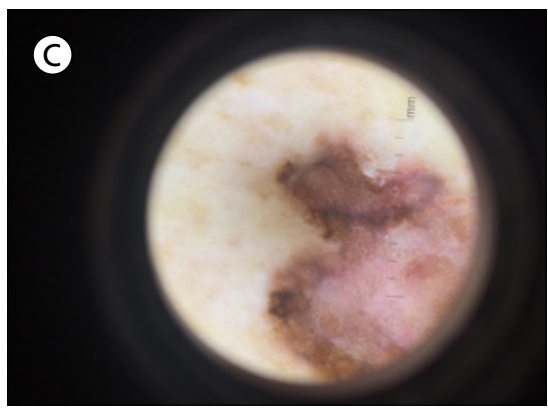

Figure 1. Dermoscopic images of melanocytic nevus and melanoma. (A) Standard dermoscopy of a melanocytic nevus (magnification 10x). (B) Videodermoscopy of the same nevus (magnification 85x). (C) Standard dermoscopy of a melanoma (magnification 10x). (D) Videodermoscopy of the same melanoma (magnification 85x). (E) Videodermoscopy of the same melanoma (magnification 140x). [Copyright: (02018 Cho et al.]

TABLE 1. Study cohort demographics

\begin{tabular}{|c|c|c|c|}
\hline & $\begin{array}{l}\text { Videodermoscopy } \\
(\mathrm{N}=30)\end{array}$ & $\begin{array}{c}\text { Standard dermoscopy } \\
(\mathrm{N}=24)\end{array}$ & P-value $^{1}$ \\
\hline Male gender, $\mathrm{N}(\%)^{1}$ & $15(50)$ & $8(33.3)$ & 0.274 \\
\hline Career Interest ${ }^{1}$ & & & 0.367 \\
\hline Medicine or related, $\mathrm{N}(\%)$ & $15(50)$ & $13(54.2)$ & \\
\hline Surgery or related, $\mathrm{N}(\%)$ & $9(30)$ & $3(12.5)$ & \\
\hline Dermatology, N (\%) & $3(10)$ & $1(4.2)$ & \\
\hline Other, $\mathrm{N}(\%)$ & $3(10)$ & $5(20.8)$ & \\
\hline Undecided, N (\%) & $5(16.7)$ & $7(29.2)$ & \\
\hline No prior dermatologist exposure, $\mathrm{N}(\%)^{1}$ & $26(86.7)$ & $21(87.5)$ & 1.000 \\
\hline No prior dermoscopy exposure, $\mathrm{N}(\%)^{1}$ & $27(90)$ & $20(83.3)$ & 0.687 \\
\hline Willingness to use dermoscopy in future practice ${ }^{2}$ & & & 0.231 \\
\hline Pre-intervention, $\mathrm{N}(\%)$ & $26(86.7)$ & $18(75)$ & \\
\hline Post-intervention, $\mathrm{N}(\%)$ & $28(93.3)$ & $21(87.5)$ & \\
\hline
\end{tabular}

${ }^{1} \mathrm{P}$-value from two-sided Fisher's exact test

${ }^{2} \mathrm{P}$-value from two proportion difference Z-test

demonstrated or discussed. The study was approved by the Stanford Institutional Review Board (IRB 40202) and the Dean's Office of the School of Medicine.

\section{Results}

The majority of subjects were interested in medicine and related subspecialties and had no prior experience working with a dermatologist or dermoscopy (Table 1). Both intervention groups reported openness to incorporating dermoscopy into future practice before and after instruction. In the combined cohort, self-reported confidence in the ability to identify benign and malignant lesions increased from disagree to agree in all lesion types, except wart, including melanocytic nevi $(\mathrm{p}=0.004)$ and melanoma $(\mathrm{p}<0.001)$ (Table 2$)$. This self-reported increase in confidence was observed in both 


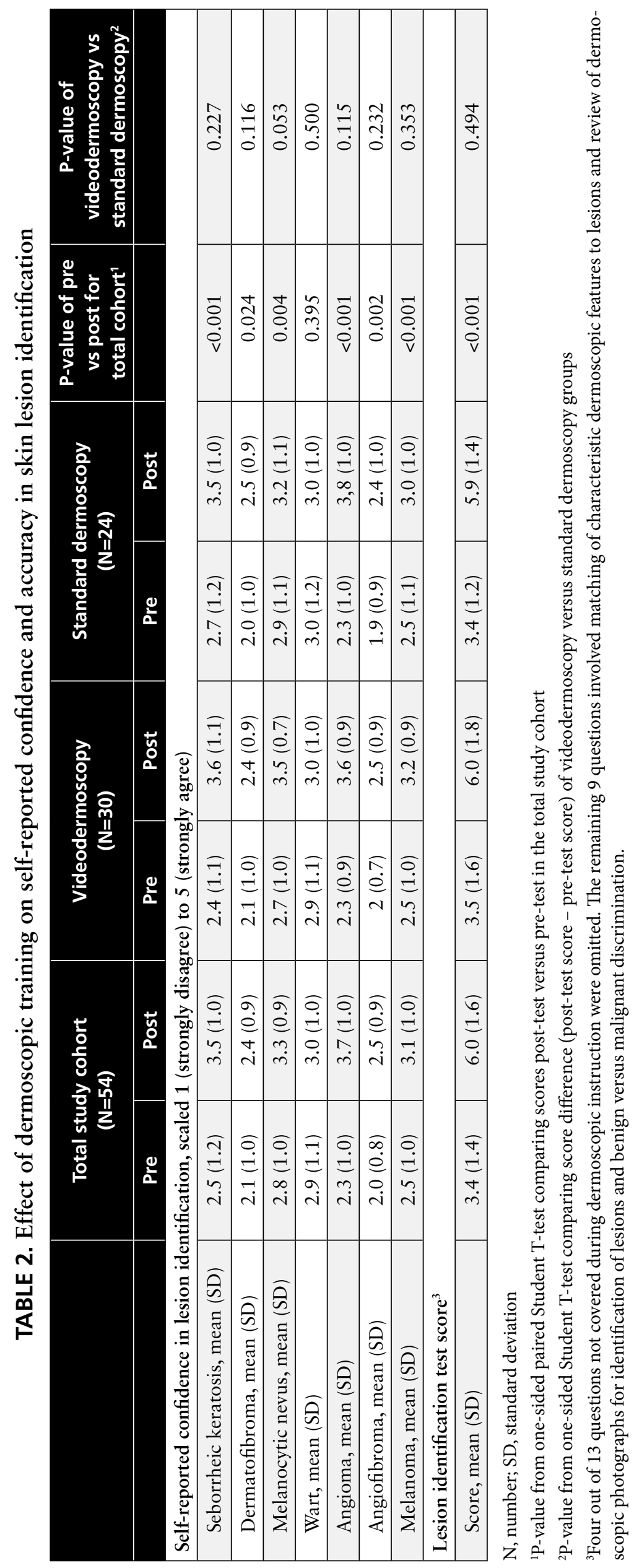


the standard dermoscopy and videodermoscopy groups, but did not differ between the groups. Confidence in identifying melanocytic nevi approached statistical significance, with a greater increase in the videodermoscopy group $(\mathrm{p}=0.053)$. The combined cohort demonstrated improvement in the ability to identify dermoscopic features of benign and malignant skin lesions with a mean (SD) pre-test score of 3.4 (1.4) and a post-test score of 6.0 (1.6) out of 9 knowledge-based questions $(\mathrm{p}<0.001)$. The change in performance was not significantly different between groups (Table 2 ).

\section{Discussion}

Brief instruction with either a standard dermatoscope or a videodermatoscope can increase medical students' confidence and accuracy in identifying benign and malignant skin lesions. Compared to prior studies, our study included lesion identification in addition to benign versus malignant distinction $[1,2]$. While there was no statistically significant difference between the use of standard dermatoscopy and videodermatoscopy in this small cohort, the subjective experience of students and the instructor included better engagement of attention and ease of instruction with videodermoscopy training compared with standard dermoscopy training.

Increase in self-reported confidence, particularly in identification of benign nevi and melanoma, highlights the need to emphasize adequate training to achieve competence in dermoscopy. While a short dermoscopic training session can improve accuracy in identifying benign non-melanocytic lesions, prior work suggests limited accuracy in melanoma identification [3]. An increase in confidence not matched by adequate training can be dangerous particularly for melanoma detection. Given the utility of dermoscopy in fields like primary care where dermoscopy use can decrease dermatology referrals and biopsies performed, adequate student training is an important consideration [4].

A limitation of the study includes the small sample sizes of the intervention groups. Further studies are needed to determine effective ways to improve medical student dermatologic education, including further examination of the potential educational benefits of videodermatoscopy given the subjective benefits noted during this study.

\section{References}

1. Liebman TN, Goulart JM, Soriano R, et al. Effect of dermoscopy education on the ability of medical students to detect skin cancer. Arch Dermatol. 2012;148:1016-1022.

2. Chen LL, Liebman TN, Soriano RP, et al. One-year follow-up of dermoscopy education on the ability of medical students to detect skin cancer. Dermatology. 2013;226:267-273.

3. Secker LJ, Buis PA, Bergman W, Kukutsch NA. Effect of a dermoscopy training course on the accuracy of primary care physicians in diagnosing pigmented lesions. Acta Derm Venereol. 2017;97:263265.

4. Chappuis P, Duru G, Marchal O, et al. Dermoscopy, a useful tool for general practitioners in melanoma screening: a nationwide survey. Br J Dermatol. 2016;175:744-750. 